\title{
WHAT IS THE PHILOSOPHY OF INFORMATION?
}

\author{
LUCIANO FLORIDI
}

\begin{abstract}
Computational and information-theoretic research in philosophy has become increasingly fertile and pervasive, giving rise to a wealth of interesting results. In consequence, a new and vitally important field has emerged, the philosophy of information (PI). This essay is the first attempt to analyse the nature of PI systematically. PI is defined as the philosophical field concerned with the critical investigation of the conceptual nature and basic principles of information, including its dynamics, utilisation, and sciences, and the elaboration and application of information-theoretic and computational methodologies to philosophical problems. I argue that PI is a mature discipline for three reasons: it represents an autonomous field of research; it provides an innovative approach to both traditional and new philosophical topics; and it can stand beside other branches of philosophy, offering a systematic treatment of the conceptual foundations of the world of information and the information society.
\end{abstract}

Keywords: computation, cyberphilosophy, dialectic, digital philosophy, information, information technology, information society, information-theoretic methodology, innovation, philosophy of AI, philosophy of computer science, philosophy of computing, philosophy of information, scholasticism.

\section{Introduction}

Computational and information-theoretic research in philosophy has become increasingly fertile and pervasive. It revitalises old philosophical questions, poses new problems, contributes to reconceptualising our world views, and has already produced a wealth of interesting and important results. ${ }^{1}$ Various labels have recently been suggested for this new field. Some follow such fashionable terminology as cyberphilosophy, digital philosophy, and computational philosophy, most express specific theoretical orientations, such as philosophy of computer science, philosophy of computing or computation, philosophy of AI, computers and philosophy, computing and philosophy, philosophy of the artificial, and android epistemology. In this essay I argue that the name philosophy of information

${ }^{1}$ See Bynum and Moor 1998, Colburn 2000, Floridi 1999 and 2002, and Mitcham and Huning 1986 for references. 
(PI) is the most satisfactory, for reasons that are fully discussed in section $5 .^{2}$

Sections 2, 3, and 4 analyse the historical and conceptual process that has led to the emergence of PI. They support the following two conclusions. First, philosophy of AI was a premature paradigm, which nevertheless paved the way for the emergence of PI. Second, PI has evolved as the most recent stage in the dialectic between conceptual innovation and scholasticism. A definition of PI is then introduced and discussed in section 5. Section 6 summarises the main conclusions issuing from the preceding discussion and indicates how PI could be interpreted as a new philosophia prima, although not from the perspective of a philosophia perennis.

The view defended in this essay is that PI is a mature discipline because (a) it represents an autonomous field (unique topics); (b) it provides an innovative approach to both traditional and new philosophical topics (original methodologies); and (c) it can stand beside other branches of philosophy, offering the systematic treatment of the conceptual foundations of the world of information and of the information society (new theories).

\section{Philosophy of Artificial Intelligence as a Premature Paradigm of PI}

André Gide once wrote that one does not discover new lands without consenting to lose sight of the shore for a very long time. Looking for new lands, Aaron Sloman in 1978 heralded the advent of a new AI-based paradigm in philosophy. In a book appropriately entitled The Computer Revolution in Philosophy, he conjectured

1. that within a few years, if there remain any philosophers who are not familiar with some of the main developments in artificial intelligence, it will be fair to accuse them of professional incompetence, and

2. that to teach courses in philosophy of mind, epistemology, aesthetics, philosophy of science, philosophy of language, ethics, metaphysics and other main areas of philosophy, without discussing the relevant aspects of artificial intelligence will be as irresponsible as giving a degree course in physics which includes no quantum theory. (Sloman 1978, 5, numbered structure added)

The prediction turned out to be inaccurate and over-optimistic, but it was far from unjustified. ${ }^{3}$

Sloman was not alone. Other researchers (cf., for example, Simon 1962, McCarthy and Hayes 1969, Pagels 1988, who argues in favour of a complexity-theory paradigm, and Burkholder 1992, who speaks of a

\footnotetext{
2 The label Philosophy of Information was first introduced in a series of papers I have given since 1996 in Italy, England, and the United States (see note 12 below).

${ }^{3}$ See also Sloman 1995 and McCarthy 1995.
} 
"computational turn") had correctly perceived that the practical and conceptual transformations caused by ICS (Information and Computational Sciences) and ICT (Information and Communication Technologies) were bringing about a macroscopic change, not only in science but in philosophy too. It was the so-called computer revolution or "information turn." Like Sloman, however, they seem to have been misguided about the specific nature of this evolution and have underestimated the unrelenting difficulties that the acceptance of a new PI paradigm would encounter.

Turing begun publishing his seminal papers in the 1930s. During the following fifty years, cybernetics, information theory, AI, system theory, computer science, complexity theory, and ICT succeeded in attracting some significant, if sporadic, interest from the philosophical community, especially in terms of philosophy of AI. ${ }^{4}$ They thus prepared the ground for the emergence of an independent field of investigation and a new computational and information-theoretic approach in philosophy. Until the 1980s, however, they failed to give rise to a mature, innovative, and influential program of research, let alone a revolutionary change of the magnitude and importance envisaged by researchers like Sloman in the 1970s. With hindsight, it is easy to see how AI could be perceived as an exciting new field of research and the source of a radically innovative approach to traditional problems in philosophy. "Ever since Alan Turing's influential paper 'Computing machinery and intelligence' [. . .] and the birth of the research field of Artificial Intelligence (AI) in the mid-1950s, there has been considerable interest among computer scientists in theorising about the mind. At the same time there has been a growing feeling amongst philosophers that the advent of computing has decisively modified philosophical debates, by proposing new theoretical positions to consider, or at least to rebut" (Torrance 1984, 11).

AI acted as a Trojan horse, introducing a more encompassing computational/informational paradigm into the philosophical citadel (earlier statements of this view can be found in Simon 1962 and 1996, Pylyshyn 1970, and Boden 1984; more recently, see McCarthy 1995 and Sloman 1995). Until the mid-1980s, however, PI was still premature and perceived as transdisciplinary rather than interdisciplinary; the philosophical and scientific communities were, in any case, not yet ready for its development; and the cultural and social contexts were equally unprepared. Each factor deserves a brief clarification.

${ }^{4}$ In 1964, introducing his influential anthology, Anderson wrote that the field of philosophy of AI had already produced more than a thousand articles (Anderson 1964, 1). No wonder that (sometimes overlapping) editorial projects have flourished. Among the available titles, the reader of this essay may wish to keep in mind Ringle 1979 and Boden 1990, which provide two further good collections of essays, and Haugeland 1981, which was expressly meant to be a sequel to Anderson 1964 and was further revised in Haugeland 1997. 
Like other intellectual enterprises, PI deals with three types of domain: topics (facts, data, problems, phenomena, observations, and the like); methods (techniques, approaches, and so on); and theories (hypotheses, explanations, and so forth). A discipline is premature if it attempts to innovate in more than one of these domains simultaneously, thus detaching itself too abruptly from the normal and continuous thread of evolution of its general field (Stent 1972). A quick look at the two points made by Sloman in his prediction shows that this was exactly what happened to PI in its earlier appearance as the philosophy of AI.

The inescapable interdisciplinarity of PI further hindered the prospects for a timely recognition of its significance. Even now, many philosophers are content to consider topics discussed in PI to be worth the attention only of researchers in English, mass media, cultural studies, computer science, or sociology departments, to mention a few examples. PI needed philosophers used to conversing with cultural and scientific issues across the boundaries, and these were not to be found easily. Too often, everyone's concern is nobody's business, and until the recent development of the information society, PI was perceived to be at too much of a crossroads of technical matters, theoretical issues, applied problems, and conceptual analyses to be anyone's own area of specialisation. PI was considered to be transdisciplinary like cybernetics or semiotics, rather than interdisciplinary like biochemistry or cognitive science. We shall return to this problem later.

Even if PI had not been too premature or allegedly so transdisciplinary, the philosophical and scientific communities at large were not yet ready to appreciate its importance. There were strong programs of research, especially in philosophies of language (logico-positivist, analytic, commonsensical, postmodernist, deconstructionist, hermeneutical, pragmatist, and so on), which attracted most of the intellectual and financial resources, kept a fairly rigid agenda, and hardly enhanced the evolution of alternative paradigms. Mainstream philosophy cannot help being conservative, not only because values and standards are usually less firm and clear in philosophy than in science, and hence more difficult to challenge, but also because, as we shall see better in section 4 , this is the context in which a culturally dominant position is often achieved at the expense of innovative or unconventional approaches. As a result, thinkers like Church, Shannon, Simon, Turing, von Neumann, and Wiener were essentially left on the periphery of the traditional canon. Admittedly, the computational turn affected science much more rapidly. This explains why some philosophically minded scientists were among the first to perceive the emergence of a new paradigm. Nevertheless, Sloman's “computer revolution" still had to wait until the 1980s to become a more widespread and mass phenomenon across the various sciences and social contexts, thus creating the right environment for the evolution of PI.

More than half a century after the construction of the first mainframes, 
the development of human society has now reached a stage in which issues concerning the creation, dynamics, management, and utilisation of information and computational resources are absolutely vital. Nonetheless, advanced societies and Western culture had to undergo a digital communications revolution before being able to appreciate in full the radical novelty of the new paradigm. The information society has been brought about by the fastest-growing technology in history. No previous generation was ever exposed to such an extraordinary acceleration of technological power over reality, with the corresponding social changes and ethical responsibilities. Total pervasiveness, flexibility, and high power have raised ICT to the status of the characteristic technology of our time, factually, rhetorically, and even iconographically. The computer presents itself as a culturally defining technology and has become a symbol of the new millennium, playing a cultural role far more influential than that of mills in the Middle Ages, mechanical clocks in the seventeenth century, and the loom or the steam engine in the age of the industrial revolution (Bolter 1984). ICS and ICT applications are nowadays the most strategic of all the factors governing science, the life of society, and their future. The most developed postindustrial societies live by information, and ICS-ICT is what keeps them constantly oxygenated. And yet, all these profound and significant transformations were barely in view two decades ago, when most philosophy departments would have considered topics in PI unsuitable areas of specialisation for a graduate student.

Too far ahead of its time, and dauntingly innovative for the majority of professional philosophers, PI wavered for some time between two alternatives. It created a number of interesting but limited research niches like philosophy of AI or computer ethics - often tearing itself away from its intellectual background. Or it was absorbed within other areas as a methodology, when PI was perceived as a computational or informationtheoretic approach to otherwise traditional topics, in classic areas like epistemology, logic, ontology, philosophy of language, philosophy of science, and philosophy of mind. Both trends further contributed to the emergence of PI as an independent field of investigation.

\section{The Historical Emergence of PI}

Ideas, as it is said, are 'in the air'. The true explanation is presumably that, at a certain stage in the history of any subject, ideas become visible, though only to those with keen mental eyesight, that not even those with the sharpest vision could have perceived at an earlier stage. (Dummett 1993, 3)

Visionaries have a hard life. If nobody else follows, one does not discover new lands but merely gets lost, at least in the eyes of those who stayed behind in the cave. It has required a third computer-related revolution (the Internet), a whole new generation of computer-literate students, teachers 
and researchers, a substantial change in the fabric of society, a radical transformation in the cultural and intellectual sensibility, and a widespread sense of crisis in philosophical circles of various orientations for the new paradigm to emerge. By the late 1980s, PI had finally begun to be acknowledged as a fundamentally innovative area of philosophical research, rather than a premature revolution. Perhaps it is useful to recall a few dates. In 1982, Time magazine named the computer "Man of the Year." In 1985, the American Philosophical Association created the Committee on Philosophy and Computers (PAC). ${ }^{5}$ In the same year, Terrell Ward Bynum, then editor in chief of Metaphilosophy, published a special issue of the journal entitled Computers and Ethics (Bynum 1985) that "quickly became the widest-selling issue in the journal's history" (Bynum 2000, see also Bynum 1998). The first conference sponsored by the Computing and Philosophy (CAP) association was held at Cleveland State University in 1986. "Its program was mostly devoted to technical issues in logic software. Over time, the annual CAP conferences expanded to cover all aspects of the convergence of computing and philosophy. In 1993, Carnegie Mellon became a host site" (CAP web site).

By the mid-1980s, the philosophical community had become fully aware and appreciative of the importance of the topics investigated by PI, and of the value of its methodologies and theories. ${ }^{6}$ PI was no longer seen as weird, esoteric, transdisciplinary, or philosophically irrelevant. Concepts or processes like algorithm, automatic control, complexity, computation, distributed network, dynamic system, implementation, information, feedback, and symbolic representation; phenomena like HCI (human-computer interaction), CMC (computer-mediated communication), computer crimes, electronic communities, and digital art; disciplines like AI and Information Theory; issues like the nature of artificial agents, the definition of personal identity in a disembodied environment, and the nature of virtual realities; models like those provided by Turing machines, artificial neural networks, and artificial life systems . . . these are just a few examples of a growing number of topics that were more and more commonly perceived as being new, of pressing interest, and academically

\footnotetext{
5 The "computer revolution" had affected philosophers as "professional knowledgeworkers" even before attracting their attention as interpreters. The charge of the APA committee was, and still is, mainly practical. The committee "collects and disseminates information on the use of computers in the profession, including their use in instruction, research, writing, and publication, and makes recommendations for appropriate actions of the Board or programs of the Association" (PAC). Note that the computer is often described as the laboratory tool for the scientific study and empirical simulation, exploration and manipulation of information structures. But then, "philosophy and computers" is like saying "philosophy and information laboratories." PI without computers is like biology without microscopes, astronomy without telescopes. But what really matters are information structures (microscopic entities, planets), not the machines used to study them.

${ }^{6}$ See, for example, Burkholder 1992, a collection of sixteen essays by twenty-eight authors presented at the first six CAP conferences; most of the papers are from the fourth one.
} 
respectable. Informational and computational concepts, methods, techniques, and theories had become powerful metaphors acting as "hermeneutic devices" through which to interpret the world. They had established a metadisciplinary, unified language that had become common currency in all academic subjects, including philosophy.

In 1998, introducing The Digital Phoenix - a collection of essays this time significantly subtitled How Computers Are Changing Philosophy Terrell Ward Bynum and James H. Moor acknowledged the emergence of $\mathrm{PI}$ as a new force in the philosophical scenario:

From time to time, major movements occur in philosophy. These movements begin with a few simple, but very fertile, ideas - ideas that provide philosophers with a new prism through which to view philosophical issues. Gradually, philosophical methods and problems are refined and understood in terms of these new notions. As novel and interesting philosophical results are obtained, the movement grows into an intellectual wave that travels throughout the discipline. A new philosophical paradigm emerges. [...] Computing provides philosophy with such a set of simple, but incredibly fertile notions - new and evolving subject matters, methods, and models for philosophical inquiry. Computing brings new opportunities and challenges to traditional philosophical activities ... changing the way philosophers understand foundational concepts in philosophy, such as mind, consciousness, experience, reasoning, knowledge, truth, ethics, and creativity. This trend in philosophical inquiry that incorporates computing in terms of a subject matter, a method, or a model has been gaining momentum steadily. (Bynum and Moor 1998, 1)

At the distance set by a textbook, philosophy often strikes the student as a discipline of endless diatribes and extraordinary claims, in a state of chronic crisis. Sub specie aeternitatis, the diatribes unfold in the forceful dynamics of ideas, claims acquire the necessary depth, the proper level of justification, and their full significance, while the alleged crisis proves to be a fruitful and inevitable dialectic between innovation and scholasticism. ${ }^{7}$ This dialectic of reflection, highlighted by Bynum and Moor, has played a major role in establishing PI as a mature area of philosophical investigation. We have seen its historical side. This is how it can be interpreted conceptually.

\section{The Dialectic of Reflection and the Emergence of PI}

In order to emerge and flourish, the mind needs to make sense of its environment by continuously investing data (affordances) with meaning. Mental life is thus the result of a successful reaction to a primary horror vacui semantici: meaningless (in the non-existentialist sense of "not-yet-

\footnotetext{
${ }^{7}$ For an interesting attempt to look at the history of philosophy from a computational perspective, see Glymour 1992.
} 
meaningful") chaos threatens to tear the Self asunder, to drown it in an alienating otherness perceived by the Self as nothingness, and this primordial dread of annihilation urges the Self to go on filling any semantically empty space with whatever meaning the Self can muster, as successfully as the cluster of contextual constraints, affordances, and the development of culture permit. This semanticisation of being, or reaction of the Self to the non-Self (to phrase it in Fichtean terms), consists in the inheritance and further elaboration, maintenance, and refinement of factual narratives (personal identity, ordinary experience, community ethos, family values, scientific theories, common-sense-constituting beliefs, and so on) that are logically and contextually (and hence sometimes fully) constrained and constantly challenged by the data that they need to accommodate and explain. Historically, the evolution of this process is ideally directed towards an ever-changing, richer, and more robust framing of the world. Schematically, it is the result of four conceptual thrusts:

(1) A metasemanticisation of narratives. The result of any reaction to being solidifies into an external reality facing the new individual Self, who needs to appropriate narratives as well, now perceived as further data-affordances that the Self is forced to semanticise. Reflection turns to reflection and recognises itself as part of the reality it needs to explain and make sense of.

(2) A de-limitation of culture. This is the process of externalisation and sharing of the conceptual narratives designed by the Self. The world of meaningful experience moves from being a private, infra-subjective and anthropocentric construction to being an increasingly inter-subjective and de-anthropocentrified reality. A community of speakers share the precious semantic resources needed to make sense of the world by maintaining, improving, and transmitting a language - with its conceptual and cultural implications - that a child learns as quickly as a shipwrecked person desperately grabs a floating plank. Narratives then become increasingly friendly because shared with other non-challenging Selves not far from one Self, rather than reassuring because inherited from some unknown deity. As "produmers" (producers and consumers) of specific narratives no longer bounded by space or time, members of a community constitute a group only apparently transphysical, in fact functionally defined by the semantic space they wish and opt (or may be forced) to inhabit. The phenomenon of globalisation is rather a phenomenon of erasure of old limits and creation of new ones, and hence a phenomenon of de-limitation of culture.

(3) A de-physicalisation of nature. The physical world of watches and cutlery, of stones and trees, of cars and rain, of the I as ID (the socially identifiable Self, with a gender, a job, a driving licence, a marital status, and so on) undergoes a process of virtualisation and distancing, in which even the most essential tools, the most dramatic experiences 
or the most touching feelings, from war to love, from death to sex, can be framed within virtual mediation, and hence acquire an informational aura. Art, goods, entertainment, news, and other Selves are placed and experienced behind a glass. On the other side of the virtual frame, objects and individuals can become fully replaceable and often absolutely indistinguishable tokens of ideal types: a watch is really a swatch, a pen is a present only insofar as it is a branded object, a place is perceived as a holiday resort, a temple turns into a historical monument, someone is a police officer, and a friend may be just a written voice on the screen of a PC. Individual entities are used as disposable instantiations of universals. The here-and-now is transformed and expanded. By speedily multitasking, the individual Self can inhabit ever more loci, in ways that are perceived synchronically even by the Self, and thus can swiftly weave different lives, which do not necessarily merge. Past, present, and future are reshaped in discrete and variable intervals of current time. Projections and indiscernible repetitions of present events expand them into the future; future events are predicted and pre-experienced in anticipatory presents; past events are registered and re-experienced in replaying presents. The nonhuman world of inimitable things and unrepeatable events is increasingly windowed, and humanity window-shops in it.

(4) A hypostatisation (embodiment) of the conceptual environment designed and inhabited by the mind. Narratives, including values, ideas, fashions, emotions, and that intentionally privileged macronarrative that is the I can be shaped and reified into "semantic objects" or "information entities," now coming closer to the interacting Selves, quietly acquiring an ontological status comparable to that of ordinary things likes clothes, cars, and buildings.

By our de-physicalising nature and embodying narratives, the physical and the cultural are realigned on the line of the virtual. In the light of this dialectic, the information society can be seen as the most recent, although not definitive, stage in a wider semantic process that makes the mental world increasingly part of, if not the environment in which more and more people tend to live. It brings history and culture, and hence time, to the fore as the result of human deeds, while pushing nature, as the unhuman, and hence physical space, into the background. In the course of its evolution, the process of semanticisation gradually leads to a temporal fixation of the constructive conceptualisation of reality into a world view, which then generates a conservative closure, scholasticism. ${ }^{8}$

Scholasticism, understood as an intellectual typology rather than a scholarly category, represents a conceptual system's inborn inertia, when

${ }^{8}$ For an enlightening discussion of contemporary scholasticism, see Rorty 1982, chaps. 2,4 , and especially 12 . 
not its rampant resistance to innovation. It is institutionalised philosophy at its worst, that is, a degeneration of what socio-linguists call, more broadly, the internal "discourse" (Gee 1998, esp. 52-53) of a community or group of philosophers. It manifests itself as a pedantic and often intolerant adherence to some discourse (teachings, methods, values, viewpoints, canons of authors, positions, theories, selections of problems, and so on), set by a particular group (a philosopher, a school of thought, a movement, a trend) at the expense of other alternatives, which are ignored or opposed. It fixes, as permanently and objectively as possible, a toolbox of philosophical concepts and vocabulary suitable for standardising its discourse (its special isms) and the research agenda of the community.

In this way, scholasticism favours the professionalisation of philosophy: scholastics are "lovers" who detest the idea of being amateurs and wish to become professional. They are suffixes: they call themselves "-ans" and place before that ending (pro-stituere) the names of other philosophers, whether they are Aristotelians, Cartesians, Kantians, Nietzscheans, Wittgensteinians, Heideggerians, or Fregeans. Followers, exegetes, and imitators of some mythicised founding fathers, scholastics find in their hands more substantial answers than new interesting questions and thus gradually become involved with the application of some doctrine to its own internal puzzles, readjusting, systematising, and tidying up a oncedynamic area of research. Scholasticism is metatheoretically acritical and hence reassuring: fundamental criticism and self-scrutiny are not part of the scholastic discourse, which, on the contrary, helps a community to maintain a strong sense of intellectual identity and a clear direction in the efficient planning and implementation of its research and teaching activities. It is a closed context: scholastics tend to interpret, criticise, and defend only views of other identifiable members of the community, thus mutually reinforcing a sense of identity and purpose, instead of directly addressing new conceptual issues that may still lack an academically respectable pedigree and hence be more challenging. This is the road to anachronism: a progressively wider gap opens up between philosophers' problems and philosophical problems. Scholastic philosophers become busy with narrow and marginal disputationes of detail that only they are keen to ask about, while failing to interact with other disciplines, new discoveries, or contemporary problems that are of lively interest outside the specialised discourse. In the end, once scholasticism is closed in on itself, its main purpose becomes quite naturally the perpetuation of its own discourse, transforming itself into academic strategy.

What has been said so far should not be confused with the naive question as to whether philosophy has lost, and hence should regain, contact with people (Adler 1979, Quine 1979). People may be curious about philosophy, but only a philosopher can fancy they might be interested in it. Scholasticism, if properly trivialised, can be pop and even trendy - after all, "trivial" should remind one of professional love - while innovative 
philosophy can bear to be esoteric. Perhaps a metaphor can help to clarify the point. Conceptual areas are like mines. Some of them are so vast and rich that they will keep philosophers happily busy for generations. Others may seem exhausted until new and powerful methods or theories allow further and deeper explorations, or lead to the discovery of problems and ideas previously overlooked. Scholastic philosophers are like wretched workers digging a nearly exhausted but not yet abandoned mine. They belong to a late generation, technically trained to work only in the narrow field in which they happen to find themselves. They work hard to gain little, and the more they invest in their meagre explorations, the more they stubbornly bury themselves in their own mine, refusing to leave their place to explore new sites. Tragically, only time will tell whether the mine is truly exhausted. Scholasticism is a censure that can be applied only post mortem.

Innovation is always possible, but scholasticism is historically inevitable. Any stage in the semanticisation of being is destined to be initially innovative if not disruptive, to establish itself as a specific dominant paradigm, and hence to become fixed and increasingly rigid, further reinforcing itself, until it finally acquires an intolerant stance towards alternative conceptual innovations and so becomes incapable of dealing with the ever-changing intellectual environment that it helped to create and mould. In this sense, every intellectual movement generates the conditions of its own senescence and replacement.

Conceptual transformations should not be too radical, lest they become premature. We have seen that old paradigms are challenged and finally replaced by further, innovative reflection only when it is sufficiently robust to be acknowledged as a better and more viable alternative to the previous stage in the semanticisation of being. Here is how Moritz Schlick clarified this dialectic at the beginning of a paradigm shift:

Philosophy belongs to the centuries, not to the day. There is no uptodateness about it. For anyone who loves the subject, it is painful to hear talk of 'modern' or 'non-modern' philosophy. The so-called fashionable movements in philosophy - whether diffused in journalistic form among the general public, or taught in a scientific style at the universities - stand to the calm and powerful evolution of philosophy proper much as philosophy professors do to philosophers: the former are learned, the latter wise; the former write about philosophy and contend on the doctrinal battlefield, the latter philosophise. The fashionable philosophic movements have no worse enemy than true philosophy, and none that they fear more. When it rises in a new dawn and sheds its pitiless light, the adherents of every kind of ephemeral movement tremble and unite against it, crying out that philosophy is in danger, for they truly believe that the destruction of their own little system signifies the ruin of philosophy itself. (Schlick 1979, 2: 491)

Three types of force, therefore, need to interact to compel a conceptual system to innovate. Scholasticism is the internal, negative force. It gradually 
fossilises thought, reinforcing its fundamental character of immobility, By making a philosophical school increasingly rigid, less responsive to the world, and more brittle, it weakens its capacity for reaction to scientific, cultural, and historical inputs, divorces it from reality, and thus prepares the ground for a solution of the crisis. Scholasticism, however, can only indicate that philosophical research has reached a stage when it needs to address new topics and problems, adopt innovative methodologies, or develop alternative explanations. It does not specify which direction the innovation should take. Historically, this is the task of two other, positive forces for innovation, external to any philosophical system: the substantial novelties in the environment of the conceptual system, occurring also as a result of the semantic work done by the old paradigm itself; and the appearance of an innovative paradigm, capable of dealing with them more successfully, and thus of disentangling the conceptual system from its stagnation.

In the past, philosophers had to take care of the whole chain of knowledge production, from raw data to scientific theories, as it were. Throughout its history, philosophy has progressively identified classes of empirical and logico-mathematical problems and outsourced their investigations to new disciplines. It has then returned to these disciplines and their findings for controls, clarifications, constraints, methods, tools, and insights. But, pace Carnap (1935) and Reichenbach (1951), philosophy itself consists of conceptual investigations whose essential nature is neither empirical nor logico-mathematical. To mis-paraphrase Hume: "If we take in our hand any volume, let us ask: Does it contain any abstract reasoning concerning quantity or number? Does it contain any experimental reasoning concerning matter of fact and existence?" If the answer is yes, then search elsewhere, because that is science, not yet philosophy.

Philosophy is not a conceptual aspirin, a super-science, or the manicure of language but the art of identifying conceptual problems and designing, proposing, and evaluating explanatory models. It is, after all, the last stage of reflection, where the semanticisation of being is pursued and kept open (Russell 1912, chap. 15). Its critical and creative investigations identify, formulate, evaluate, clarify, interpret, and explain problems that are intrinsically capable of different and possibly irreconcilable solutions, problems that are genuinely open to debate and honest disagreement, even in principle. These investigations are often entwined with empirical and logicomathematical issues and so are scientifically constrained, but, in themselves, they are neither. They constitute a space of inquiry broadly definable as normative. It is an open space: anyone can step into it, no matter what the starting point is, and disagreement is always possible. It is also a dynamic space, for when its cultural environment changes, philosophy follows suit and evolves. ${ }^{9}$ Thus, in Bynum's and Moor's felicitous

9 This normative space should not be confused with Sellars's famous "space of reasons": "In characterizing an episode or a state as that of knowing, we are not giving an empirical 
metaphor, philosophy is indeed like a phoenix: it can flourish only by constantly re-engineering itself. A philosophy that is not timely but timeless is not an impossible philosophia perennis, which claims universal validity over past and future intellectual positions, but a stagnant philosophy, unable to contribute to, keep track of, and interact with the cultural evolution that philosophical reflection itself has helped to bring about, and hence unable to grow.

Having outsourced various forms of knowledge, philosophy's pulling force of innovation has necessarily become external. It has been made so by philosophical reflection itself. This is the full sense in which Hegel's metaphor of the Owl of Minerva is to be interpreted. In the past, the external force has been represented by such factors as Christian theology, the discovery of other civilisations, the scientific revolution, the foundational crisis in mathematics and the rise of mathematical logic, evolutionary theory, the emergence of new social and economic phenomena, and the theory of relativity, to mention just a few of the most obvious examples. Nowadays the pulling force of innovation is represented by the complex world of information and communication phenomena, their corresponding sciences and technologies, and the new environments, social life, and existential and cultural issues that they have brought about. This is why PI can present itself as an innovative paradigm.

\section{The Definition of PI}

Once a new area of philosophical research is brought into being by the interaction between scholasticism and some external force, it evolves into a well-defined field, possibly interdisciplinary but still autonomous, only if (i) it is able to appropriate an explicit, clear, and precise interpretation not of a scholastic Fach (Rorty 1982, chap. 2) but of the classic "ti esti," thus presenting itself as a specific "philosophy of"; (ii) the appropriated interpretation becomes an attractor towards which investigations in the new field can usefully converge; (iii) the attractor proves sufficiently influential to withstand centrifugal forces that may attempt to reduce the new field to other fields of research already well established; and (iv) the new field is rich enough to be organised in clear subfields and hence allow for specialisation.

description of that episode or state; we are placing it in the logical space of reasons of justifying and being able to justify what one says" (Sellars 1963, 169). Our normative space is a space of design, where rational and empirical affordances, constraints, requirements, and standards of evaluation all play an essential role in the construction and evaluation of knowledge. It only partly overlaps with Sellars's space of reasons in that the latter includes more (e.g., mathematical deduction counts as justification, and in Sellars's space we find intrinsically decidable problems) and less, since in the space of design we find issues connected with creativity and freedom not clearly included in Sellars's space. For a discussion of Sellars's "space of reasons," see Floridi 1996, esp. chap. 4, and McDowell 1994, esp. the new introduction. 
Questions like "What is the nature of being?", "What is the nature of knowledge?", "What is the nature of right and wrong?", and "What is the nature of meaning?" are field questions. They satisfy the previous conditions, and so they have guaranteed the stable existence of their corresponding disciplines. Other questions, such as "What is the nature of the mind?", "What is the nature of beauty and taste?", and "What is the nature of a logically valid inference?" have been subject to fundamental re-interpretations, which have led to profound transformations in the definition of philosophy of mind, aesthetics, and logic. Still other questions, like "What is the nature of complexity?", "What is the nature of life?", "What is the nature of signs?", and "What is the nature of control systems?" have turned out to be transdisciplinary rather than interdisciplinary. Failing to satisfy at least one of the previous four conditions, they have struggled to establish their own autonomous fields. The question is now whether PI itself satisfies (i) to (iv). A first step towards a positive answer requires a further clarification.

Philosophy appropriates the "ti esti" question essentially in two ways, phenomenologically and metatheoretically. Philosophy of language and epistemology are two examples of "phenomenologies," or philosophies of a phenomenon. Their subjects are meaning and knowledge, not linguistic theories or cognitive sciences. Philosophy of physics and philosophy of social science, on the other hand, are plain instances of "metatheories." They investigate problems arising from organised systems of knowledge, which in their turn investigate natural or human phenomena.

Some other philosophical branches, however, show only a tension towards the two poles, often combining phenomenological and metatheoretical interests. This is the case with philosophy of mathematics and philosophy of logic, for example. Like PI, their subjects are old, but they have acquired their salient features and become autonomous fields of investigation only very late in the history of thought. These philosophies show a tendency to work on specific classes of first-order phenomena, but they also examine these phenomena working their way through methods and theories, by starting from a metatheoretical interest in specific classes of second-order theoretical statements concerning those very same classes of phenomena. The tension pulls each specific branch of philosophy towards one or the other pole. Philosophy of logic, to rely on the previous example, is metatheoretically biased. It shows a constant tendency to concentrate primarily on conceptual problems arising from logic understood as a specific mathematical theory of formally valid inferences, whereas it pays little attention to problems concerning logic as a natural phenomenon, what one may call, for want of a better description, rationality. Vice versa, PI, like philosophy of mathematics, is phenomenologically biased. It is primarily concerned with the whole domain of first-order phenomena represented by the world of information, computation, and the information society, although it addresses its problems by starting from the 
vantage point represented by the methodologies and theories offered by ICS and can be seen to incline towards a metatheoretical approach, insofar as it is methodologically critical towards its own sources.

The following definition attempts to capture the clarifications introduced so far:

(D) philosophy of information (PI) $=$ def. the philosophical field concerned with (a) the critical investigation of the conceptual nature and basic principles of information, including its dynamics, utilisation, and sciences, and (b) the elaboration and application of informationtheoretic and computational methodologies to philosophical problems.

Some clarifications are in order. The first half of the definition concerns philosophy of information as a new field. PI appropriates an explicit, clear, and precise interpretation of the "ti esti" question, namely, "What is the nature of information?" This is the clearest hallmark of a new field. Of course, as with any other field questions, this too serves only to demarcate an area of research, not to map its specific problems in detail (Floridi 2001). PI provides critical investigations that are not to be confused with a quantitative theory of data communication (information theory). On the whole, its task is to develop not a unified theory of information but rather an integrated family of theories that analyse, evaluate, and explain the various principles and concepts of information, their dynamics and utilisation, with special attention to systemic issues arising from different contexts of application and interconnections with other key concepts in philosophy, such as being, knowledge, truth, life, and meaning.

Recent surveys have shown no consensus on a single, unified definition of information. ${ }^{10}$ This is hardly surprising. Information is such a powerful concept that, as an explicandum, it can be associated with several explanations, depending on the cluster of requirements and desiderata that orientate a theory (Bar-Hillel and Carnap 1953, Szaniawski 1984). Claude Shannon, for example, remarked,

The word "information" has been given different meanings by various writers in the general field of information theory. It is likely that at least a number of these will prove sufficiently useful in certain applications to deserve further study and permanent recognition. It is hardly to be expected that a single concept of information would satisfactorily account for the numerous possible applications of this general field. (From "The Lattice Theory of Information," in Shannon 1993, 180)

${ }^{10}$ For some reviews of the variety of meanings and the corresponding different theoretical positions, see Braman 1989, Losee 1997, Machlup 1983, NATO 1974, 1975, 1983, Schrader 1984, Wellisch 1972, Wersig and Neveling 1975. I have defended a revision of the definition of semantic information as meaningful data in Floridi (forthcoming). 
Polysemantic concepts like information can be fruitfully investigated only in relation to well-specified contexts of use.

By "dynamics of information" the definition refers to: (i) the constitution and modelling of information environments, including their systemic properties, forms of interaction, internal developments, and so on; (ii) information life cycles, that is, the series of various stages in form and functional activity through which information can pass, from its initial occurrence to its final utilisation and possible disappearance, ${ }^{11}$ and (iii) computation, both in the Turing-machine sense of algorithmic processing and in the wider sense of information processing. This is a crucial specification. Although a very old concept, information has finally acquired the nature of a primary phenomenon thanks to the sciences and technologies of computation and ICT. Computation has, therefore, attracted much philosophical attention in recent years. Nevertheless, PI privileges "information" over "computation" as the pivotal topic of the new field because it analyses the latter as presupposing the former. PI treats computation as only one (although perhaps the most important) of the processes in which information can be involved. Thus, the field should be interpreted as a philosophy of information rather than just of computation, in the same sense in which epistemology is the philosophy of knowledge, not just of perception.

From an environmental perspective, PI is prescriptive about, and legislates on, what may count as information, and how information should be adequately created, processed, managed, and used. ${ }^{12}$ PI's phenomenological bias, however, does not mean that it fails to provide critical feedback. On the contrary, methodological and theoretical choices in ICS are also profoundly influenced by the kind of PI a researcher adopts more or less consciously. It is therefore essential to stress that PI critically evaluates, shapes, and sharpens the conceptual, methodological, and theoretical basis of ICS - in short, that it also provides a philosophy of ICS, as this has been plain since early work in the area of philosophy of AI (Colburn 2000).

It is worth stressing here that an excessive concern with the metatheoretical aspects of PI may lead one to miss the important fact that it is perfectly legitimate to speak of PI even in authors who lived centuries before the information revolution. Hence it will be extremely fruitful to develop a historical approach and trace PI's diachronic evolution, so long as the technical and conceptual frameworks of ICS are not anachronistically applied

${ }^{11}$ A typical life cycle includes the following phases: occurring (discovering, designing, authoring, etc.), processing and managing (collecting, validating, modifying, organising, indexing, classifying, filtering, updating, sorting, storing, networking, distributing, accessing, retrieving, transmitting, etc.), and using (monitoring, modelling, analysing, explaining, planning, forecasting, decision making, instructing, educating, learning, etc.).

${ }^{12}$ Following this research, Herold 2001 has defined librarianship as applied philosophy of information and has suggested that "librarianship, as an applied PI, seems to be the last of all disciplines to traverse intellectual history and digest its paradigms." 
but are used to provide the conceptual method and privileged perspective to evaluate in full the reflections that were developed on the nature, dynamics, and utilisation of information before the digital revolution (consider, for example, Plato's Phaedrus, Descartes's Meditations, Nietzsche's On the Use and Disadvantage of History for Life, and Popper's conception of a third world). This is significantly comparable with the development undergone by other philosophical fields, like philosophy of language, philosophy of biology, and philosophy of mathematics.

The second half of the definition indicates that PI is not only a new field but provides an innovative methodology as well. Research into the conceptual nature of information and its dynamics and utilisation is carried on from the vantage point represented by the methodologies and theories offered by ICS and ICT (see, for example, Grim, Mar, and St. Denis 1998). This perspective affects other philosophical topics as well. Informationtheoretic and computational methods, concepts, tools, and techniques have already been developed and applied in many philosophical areas, to extend our understanding of the cognitive and linguistic abilities of humans and animals and the possibility of artificial forms of intelligence (philosophy of AI; information-theoretic semantics; information-theoretic epistemology; dynamic semantics); to analyse inferential and computational processes (philosophy of computing; philosophy of computer science; information-flow logic; situation logic); to explain the organizational principles of life and agency (philosophy of artificial life; cybernetics and philosophy of automata; decision and game theory); to devise new approaches to modelling physical and conceptual systems (formal ontology; theory of information systems; philosophy of virtual reality); to formulate the methodology of scientific knowledge (model-based philosophy of science; computational methodologies in philosophy of science); and to investigate ethical problems (computer and information ethics; artificial ethics), aesthetic issues (digital multimedia/hypermedia theory; hypertext theory and literary criticism), and psychological, anthropological, and social phenomena characterising the information society and human behaviour in digital environments (cyberphilosophy). Indeed, the presence of these branches shows that PI satisfies criterion (iv). As a new field, it provides a unified and cohesive theoretical framework that allows further specialisation.

PI possesses one of the most powerful conceptual vocabularies ever devised in philosophy. This is because we can rely on informational concepts whenever a complete understanding of some series of events is unavailable or unnecessary for providing an explanation. In philosophy, this means that virtually any issue can be rephrased in informational terms. This semantic power is a great advantage of PI understood as a methodology (see the second half of the definition). It shows that we are dealing with an influential paradigm, describable in terms of an informational philosophy. But it may also be a problem, because a metaphorically pan- 
informational approach can lead to a dangerous equivocation - namely, thinking that since any $\mathrm{x}$ can be described in (more or less metaphorically) informational terms, the nature of any $\mathrm{x}$ is genuinely informational. And the equivocation obscures PI's specificity as a philosophical field with its own subject. PI runs the risk of becoming synonymous with philosophy. The best way of avoiding this loss of identity is to concentrate on the first half of the definition. PI as a philosophical discipline is defined by what a problem is (or can be reduced to be) about, not by how the problem is formulated. Although many philosophical issues seem to benefit greatly from an informational analysis, in PI information theory provides a literal foundation, not just a metaphorical superstructure. PI presupposes that a problem or an explanation can be legitimately and genuinely reduced to an informational problem or explanation. So the criterion to test the soundness of the informational analysis of $\mathrm{x}$ is not to check whether $\mathrm{x}$ can be formulated in information terms but to ask what it would be like for $\mathrm{x}$ not to have an informational nature at all. With this criterion in mind, I have provided a sample of some interesting questions in Floridi 2001.

\section{Conclusion: PI as Philosophia Prima}

Philosophers have begun to address the new intellectual challenges arising from the world of information and the information society. PI attempts to expand the frontier of philosophical research not by putting together preexisting topics, and thus reordering the philosophical scenario, but by enclosing new areas of philosophical inquiry - which have been struggling to be recognised and have not yet found room in the traditional philosophical syllabus - and by providing innovative methodologies to address traditional problems from new perspectives. Is the time ripe for the establishment of PI as a mature field? We have seen that the answer can be affirmative because our culture and society, the history of philosophy, and the dynamic forces regulating the development of the philosophical system have been moving towards it. But then, what kind of PI can be expected to develop? An answer to this question presupposes a much clearer view of PI's position in the history of thought, a view probably obtainable only a posteriori. Here it might be sketched by way of guesswork.

We have seen that philosophy grows by impoverishing itself. This is only an apparent paradox: the more complex the world and its scientific descriptions turn out to be, the more essential the level of the philosophical discourse understood as philosophia prima must become, ridding itself of unwarranted assumptions and misguided investigations that do not properly belong to the normative activity of conceptual modelling. The strength of the dialectic of reflection, and hence the crucial importance of one's historical awareness of it, lies in this transcendental regress in search of increasingly abstract and more streamlined conditions of possibility of the available narratives, in view not only of their explanation but also of 
their modification and innovation. How has the regress developed? The scientific revolution made seventeenth-century philosophers redirect their attention from the nature of the knowable object to the epistemic relation between it and the knowing subject, and hence from metaphysics to epistemology. The subsequent growth of the information society and the appearance of the infosphere, the semantic environment in which millions of people spend their time nowadays, have led contemporary philosophy to privilege critical reflection first on the domain represented by the memory and languages of organised knowledge, the instruments whereby the infosphere is managed - thus moving from epistemology to philosophy of language and logic (Dummett 1993) - and then on the nature of its very fabric and essence, information itself. Information has thus arisen as a concept as fundamental and important as being, knowledge, life, intelligence, meaning, and good and evil - all pivotal concepts with which it is interdependent - and so equally worthy of autonomous investigation. It is also a more impoverished concept, in terms of which the others can be expressed and interrelated, when not defined. In this sense, Evans was right:

Evans had the idea that there is a much cruder and more fundamental concept than that of knowledge on which philosophers have concentrated so much, namely the concept of information. Information is conveyed by perception, and retained by memory, though also transmitted by means of language. One needs to concentrate on that concept before one approaches that of knowledge in the proper sense. Information is acquired, for example, without one's necessarily having a grasp of the proposition which embodies it; the flow of information operates at a much more basic level than the acquisition and transmission of knowledge. I think that this conception deserves to be explored. It's not one that ever occurred to me before I read Evans, but it is probably fruitful. That also distinguishes this work very sharply from traditional epistemology. (Dummett 1993, 186)

This is why PI can be introduced as the forthcoming philosophia prima, both in the Aristotelian sense of the primacy of its object - information which PI claims to be a fundamental component in any environment, and in the Cartesian-Kantian sense of the primacy of its methodology and problems, as PI aspires to provide a most valuable, comprehensive approach to philosophical investigations.

PI, understood as a foundational philosophy of information design, can explain and guide the purposeful construction of our intellectual environment, and it can provide the systematic treatment of the conceptual foundations of contemporary society. It enables humanity to make sense of the world and construct it responsibly, a new stage in the semanticisation of being. Clearly, PI promises to be one of the most exciting and fruitful areas of philosophical research of our time. If what has been argued in this essay is correct, its current development may be delayed but is inevitable, and it 
will affect the overall way in which we address both new and old philosophical problems, bringing about a substantial innovation of the philosophical system. This will represent the information turn in philosophy. ${ }^{13}$

Faculty of Philosophy

Department of Computer Science

Programme in Comparative Media Law and Policy

Wolfson College, University of Oxford

Oxford OX2 6UD

$U K$

luciano.floridi@philosophy.oxford.ac.uk

\section{References}

Adler, M. 1979. "Has Philosophy Lost Contact With People?” Long Island Newsday, 18 November.

Anderson, A. R. 1964. Minds and Machines. Contemporary Perspectives in Philosophy Series. Englewood Cliffs: Prentice-Hall.

Bar-Hillel, Y. 1964. Language and Information. Reading, Mass., and London: Addison-Wesley.

Bar-Hillel, Y., and Carnap, R. 1953. "An Outline of a Theory of Semantic Information." Reprinted in Bar-Hillel 1964, 221-74; page references are to this edition.

Boden, M. A. 1984. "Methodological Links between AI and Other Disciplines." In The Study of Information: Interdisciplinary Messages, edited by F. Machlup and V. Mansfield. New York: John Wiley and Sons. Reprinted in Burkholder 1992.

1990. The Philosophy of Artificial Intelligence: Oxford Readings in Philosophy. Oxford: Oxford University Press.

Bolter J. D. 1984. Turing's Man: Western Culture in the Computer Age. Chapel Hill: University of North Carolina Press.

${ }^{13}$ I discussed previous versions of this article on many occasions: at the University of Bari, where I was invited to give a series of lectures entitled Epistemology and Information Technology during the 1996-1997 academic year, and then at the University of Rome III, when I gave a course on the philosophy of information as visiting professor in epistemology, in 1999-2000; at the Applied Logic Colloquium (Queen Mary and Westfield College, London University, 26 November 1999); at Computing in Philosophy: One-day colloquium on the philosophical implications of computing and its uses and consequences for philosophical studies (King's College, London University, 19 February 1999); at the 1999 APA Eastern Division Meeting, special session arranged by the APA Committee on Philosophy and Computers (Boston, 28 December 1999); and at the Fourth World Multiconference on Systemics, Cybernetics, and Informatics (Orlando, Fla.: 23-26 July 2000). I am very grateful to the organisers of these meetings and the participants for their feedback. Charles Ess, Jim Fetzer, Ken Herold, and Jim Moor read the final version and made very valuable comments. All remaining errors are mine. This research has been partly supported by two grants, one from the Coimbra Group, Pavia University, and one from Wolfson College, Oxford. 
Braman, S. 1989. "Defining Information.” Telecommunications Policy 13: 233-42.

Burkholder, L., ed. 1992. Philosophy and the Computer. Boulder, San Francisco, and Oxford: Westview Press.

Bynum, T. W. 1998. "Global Information Ethics and the Information Revolution." In Bynum and Moor 1998, 274-89.

- 2000. "A Very Short History of Computer Ethics." APA Newsletters on Philosophy and Computers 99, no. 2 (Spring).

the October 1985 issue of Metaphilosophy.

Bynum, T. W., and Moor, J. H., eds. 1998. The Digital Phoenix: How Computers Are Changing Philosophy. Oxford: Blackwell.

CAP. Web site of the Computing and Philosophy annual conference series, http://www.lcl.cmu.edu/caae/cap/CAPpage.html.

Carnap. R. 1935. "The Rejection of Metaphysics." Chapter in Philosophy and Logical Syntax. Reprinted 1997. Bristol: Thoemmes Press.

Colburn, T. R. 2000. Philosophy and Computer Science. Armonk, N.Y., and London: M. E. Sharpe.

Dummett, M. 1993. Origins of Analytical Philosophy. London: Duckworth.

Floridi, L. 1996. Scepticism and the Foundation of Epistemology: A Study in the Metalogical Fallacies. Leiden: Brill.

- 1999. Philosophy and Computing: An Introduction. London and New York: Routledge.

- 2001. "Open Problems in the Philosophy of Information." The Herbert A. Simon Lecture on Computing and Philosophy, CAP meeting, Carnegie Mellon University, 10 August 2001, http://caae.phil. cmu.edu/caae/CAP/.

—_. Forthcoming. "Is Information Meaningful Data?". Preprint available at http://www.wolfson.ox.ac.uk/ floridi/pdf/iimd.pdf.

- ed. 2002. The Blackwell Guide to the Philosophy of Computing and Information. Oxford: Blackwell.

Gee, J. P. 1998. "What is Literacy?" In Negotiating Academic Literacies: Teaching and Learning Across Languages and Cultures, edited by V. Zamel and R. Spack, 51-59. Mahwah, N.J.: Erlbaum.

Glymour, C. N. 1997. Thinking Things Through: An Introduction to Philosophical Issues and Achievements. Cambridge, Mass.: MIT Press.

Grim, P., G. Mar, and P. St. Denis. 1998. The Philosophical Computer. Cambridge, Mass.: MIT Press.

Haugeland, J. 1981. Mind Design: Philosophy, Psychology, Artificial Intelligence, Montgomery, Vt.: Bradford Books.

__ 1997. Mind Design II: Philosophy, Psychology, Artificial Intelligence, Cambridge, Mass.: MIT Press.

Herold, K. R. 2001. "Librarianship and the Philosophy of Information." 
Library Philosophy and Practice 3, no. 2. Available at http://www.uidaho.edu/ mbolin/lppv3n2.htm.

Kuhn, T. S. 1970. The Structure of Scientific Revolutions. Second edition. Chicago: University of Chicago Press.

Losee, R. M. 1997. "A Discipline Independent Definition of Information." Journal of the American Society for Information Science 48, no. 3: 254-69.

Machlup, F. 1983. "Semantic Quirks in Studies of Information." In The Study of Information: Interdisciplinary Messages, edited by F. Machlup and U. Mansfield, 641-71 New York: John Wiley.

McCarthy, J. 1995. "What Has AI in Common with Philosophy?" Proceedings of the 14th International Joint Conference on AI. Montreal, August 1995. Available at http://www-formal.stanford.edu/jmc/ aiphil.html.

_ Standpoint of Artificial Intelligence." Machine Intelligence 4: 463-502.

McDowell, J. 1994. Mind and World. Cambridge, Mass: Harvard University Press.

Mitcham, C., and A. Huning, eds. 1986. Philosophy and Technology II: Information Technology and Computers in Theory and Practice. Dordrecht and Boston: Reidel.

NATO. 1974. Advanced Study Institute in Information Science, Champion, 1972. Information Science: Search for Identity, edited by A. Debons. New York: Marcel Dekker.

__ 1975. Advanced Study Institute in Information Science, Aberystwyth, 1974. Perspectives in Information Science, edited by A. Debons and W. J. Cameron. Leiden: Noordhoff.

- 1983. Advanced Study Institute in Information Science, Crete, 1978. Information Science in Action: Systems Design, edited by A. Debons and A. G. Larson. Boston: Martinus Nijhoff.

PAC. Web site of the American Philosophical Association Committee on Philosophy and Computers, http://www.apa.udel.edu/apa/governance/ committees/computers/.

Quine, W. V. O. 1979. "Has Philosophy Lost Contact with People?" Long Island Newsday, 18 November. The article was modified by the editor. The original version appears as essay no. 23 in Theories and Things. Cambridge, Mass.: Harvard University Press, 1981.

Reichenbach, H. 1951. The Rise of Scientific Philosophy. Berkeley: University of California Press.

Ringle, M. 1979. Philosophical Perspectives in Artificial Intelligence. Atlantic Highlands, N.J.: Humanities Press.

Rorty, R. 1982. Consequences of Pragmatism. Brighton: Harvester Press.

Russell, B. 1912. The Problems of Philosophy. Oxford: Oxford University Press.

Schlick, M. 1979. "The Vienna School and Traditional Philosophy." 
English translation by P. Heath. In Philosophical Papers. 2 volumes. Dordrecht: Reidel. Originally published in 1937.

Schrader, A. 1984. "In Search of a Name: Information Science and Its Conceptual Antecedents." Library and Information Science Research 6: 227-71.

Shannon, C. E. 1993. Collected Papers. Edited by N. J. A. Sloane and A. D. Wyner. Los Alamos, Calif.: IEEE Computer Society Press.

Simon H. A. 1962. "The Computer as a Laboratory for Epistemology." First draft. Revised and published in Burkholder 1992, 3-23.

—. 1996. The Sciences of the Artificial. Cambridge, Mass.: MIT Press. Sloman A. 1978. The Computer Revolution in Philosophy. Atlantic Highlands, N.J.: Humanities Press.

. 1995. "A Philosophical Encounter: An Interactive Presentation of Some of the Key Philosophical Problems in AI and AI Problems in Philosophy." Proceedings of the 14th International Joint Conference on AI. Montreal, August 1995. Available at http://www.cs.bham.ac.uk/ $\sim$ axs/cog_affect/ijcai95.text.

Stent, G. 1972. "Prematurity and Uniqueness in Scientific Discovery." Scientific American (December): 84-93.

Szaniawski, K. 1984. "On Defining Information." Now in Szaniawski 1998.

1998. On Science, Inference, Information and Decision Making: Selected Essays in the Philosophy of Science, edited by A. Chmielewski and J. Wolenski. Dordrecht: Kluwer.

Torrance, S. B. 1984. The Mind and the Machine: Philosophical Aspects of Artificial Intelligence. Chichester, West Sussex, and New York: Ellis Horwood Halsted Press.

Wellisch, H. 1972. "From Information Science to Informatics." Journal of Librarianship 4: 157-87.

Wersig, G., and U. Neveling. 1975. "The Phenomena of Interest to Information Science.” Information Scientist 9: 127-40. 